\title{
OPTIMIZATION OF SURFACE ROUGHNESS OF EN-40 IN WIRE-EDM
}

\author{
Syed Asghar Husain Rizvi ${ }^{1}$, Bhanu Pratap Singh ${ }^{2}$, Mohd. Ziaulhaq ${ }^{3}$ \\ ${ }^{I}$ Department of Mechanical Engineering, Ambalika Institute of Management and Technology, Lucknow \\ ${ }^{2}$ Department of Mechanical Engineering, Azad Institute of Engineering and Technology, Lucknow \\ ${ }^{3}$ Department of Mechanical Engineering, Azad Institute of Engineering and Technology, Lucknow
}

\begin{abstract}
Wire-EDM is used to machine and cut hard conductive metals that are difficult to cut using conventional methods. The machine is also specialized in cutting complex contours that would be difficult to be produced by using conventional cutting methods. WireEDM is a type of non-contact non-conventional machining process that produces high quality products, which are difficult to get by the use of conventional machining processes. This study on Wire EDM with EN-40 as work material and brass wire as tool is done to analyze the influence of process parameters on surface quality. The experimental results concluded that the surface roughness is majorly influenced by the peak current. Pulse on duration was least influencing parameter for surface roughness. Voltage is the second most dominating parameter for surface roughness. It was also observed that larger craters were obtained at higher current.
\end{abstract}

Keywords: Wire-EDM, Surface Roughness, EN-40.

\section{INTRODUCTION}

Wire-EDM is a variation of EDM which uses a thin wire which serves as the tool or electrode. Brass wires are used and the wire is slowly fed through the material and the sparks through the wire cuts the work material. Wire Cut is usually performed in a bath of water. The material is removed by the action of high energy electrical sparks. Melting and evaporation of the material is caused by intense heat generated near the sparking zone.

Majority of work performed on Wire-EDM are for increasing the productivity and for improving the surface quality produced by machine. Continuous studies have been performed to improve the material removal efficiency and surface finish.

Manoj Malik et al [1] conducted experiment on Tungsten Carbide Ceramic with graphite as electrode and concluded that peak current is the major influencing factor affecting MRR and EWR while pulse duty factor is the least affecting factor. Further they concluded that the pulse on duration is most significant factor that affects the surface roughness of the material while duty factor affect is least. In another investigation carried by K. Kumar et al [2] concluded that factors like speed, feed, pulse on and off time play a significant role for MRR and surface roughness. The investigation conducted by $\mathrm{H}$. Singh et al [3] found that wire feed and wire tension have least effect on the material removal rate while pulse on time parameter has direct effect on the material removal rate. In a study conducted by Scott et al [4] who developed mathematical models to analyze MRR and surface finish of D-2 tool steel at different machining conditions. It was concluded that there are no single combination of levels of the factors that are optimal under all situations. Lin and Lin [5] used a new approach for optimizing the electrical discharge machining process using multiple performance characteristics based on the grey scale analysis orthogonal array. Ramakrishnan and Karunamoorthy [6] analyzed the multi objective optimization of the WEDM process and from the study it was identified that the pulse on duration and current intensity majorly influenced the performance measures more than other parameters. Anoop Mathew Kurian et al [7] studied Surface Roughness of Stainless Steel 15-5 PH. The parameter pulse duration was found to be the most effective on the surface roughness followed by the discharge current. In an experimental study Dhruv H. Gajjar et al [8] carried out experiments on EN-31 using Molybdenum wire to optimize MRR, surface roughness and kerf width in wireEDM and concluded that more spark energy is generated with increase of pulse on time. MRR, kerf width and surface roughness increases with pulse on time. Surface roughness increases with increase of pulse on time because broader and deeper craters. R.Nagaraja et al [9] found that the wire feed was the most significant parameter for surface roughness while machining bronze-alumina $\left(\mathrm{Al}_{2} \mathrm{O}_{3}\right)$ MMC. Parveen $\mathrm{Kr}$. Saini et al [10] carried their experiments on Titanium alloy found that with increase in short pulse time and pulse width results higher MRR. Muhammad Qaiser Saleem et al [11] carried a comparative study on Al-7075 and D-2 to find influence of parameters on MRR. They concluded that the tensile strength of the wire has an effect on surface quality, with wire of higher tensile strength resulting into a higher surface finish. They also concluded that the higher value of the work material hardness results in good surface finish. It was found that the Tensile strength of the wire is not seen to be affecting the MRR much. Rajaneesh N. Marigoudara et al [12] in their study of MRR and surface roughness in machining of ZA43/ SiCp composite concluded that MRR increases with increase in peak current and pulse on duration and decreases with increase in pulse off time. It was also observed that the MRR decreases with increase in reinforcement content in MMC. The surface gets rough with 
increase in current. They also found that $\mathrm{SiC}$ in MMC is an influencing parameter on surface roughness.

\section{EXPERIMENTAL DETAILS}

Work Material: EN-40 of size of $10 \mathrm{~mm}$ diameter and 5 mm thickness

Tool Material: Brass wire of $0.18 \mathrm{~mm}$ diameter.

Machine Used: ECOCUT CNC Pulse Generator ELPULS15 .

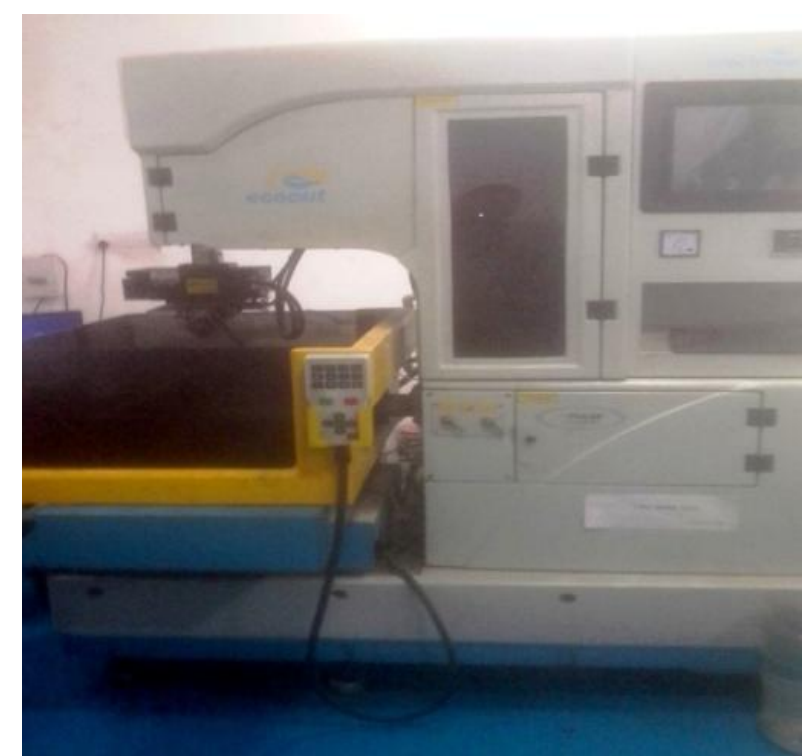

Fig 1 Setup of ECOCUT CNC Pulse Generator ELPULS-15

This analysis uses Taguchi approach that deals with responses influenced by multi-variables effectively. It is a powerful design of experiments tool, which is used to determine optimal machining parameter by a simple, efficient and systematic approach.

The current study considers three principal Wire-EDM parameters that affect its surface finish. They are peak current, pulse on duration and voltage. Table 1 summarizes the levels of process parameters set as per Taguchi $\mathrm{L}_{9}$ orthogonal array.

Table 1: The levels of Wire-EDM parameters

\begin{tabular}{|l|l|lll|}
\hline Parameters & Unit & \multicolumn{3}{|l|}{ Levels } \\
\hline Peak Current & $\mathrm{A}$ & 1 & 5 & 9 \\
\hline Pulse on Time & $\mu \mathrm{sec}$ & 10 & 15 & 20 \\
\hline Volatge $\left(V_{g}\right)$ & $\mathrm{V}$ & 100 & 125 & 150 \\
\hline
\end{tabular}

Scanning electron microscopy (SEM) was also performed so as to analyze the craters formed by the machining.

The surface roughness is measured by the stylus type Mitutoyo 178-602 surface roughness tester.

\section{RESULTS AND DISCUSSIONS}

\subsection{Surface Roughness}

The surface roughness is an important factor that is considered while machining. In present investigation, as the current and pulse on duration is increased, surface roughness obtained tends to increase at every level. This is due to the effect of sparks that leads to larger crater and thus a rough surface is obtained. Table 2 shows the mean $\mathrm{S} / \mathrm{N}$ ratio for surface roughness.

Table 2 Calculation of mean $\mathrm{S} / \mathrm{N}$ ratio for Surface Roughness

\begin{tabular}{|l|l|l|l|}
\hline Level & Current & $\begin{array}{l}\text { Pulse on } \\
\text { time }\end{array}$ & $\begin{array}{l}\text { Voltage } \\
(\text { V) }\end{array}$ \\
\hline $\mathbf{1}$ & -16.73 & -17.16 & -16.87 \\
\hline $\mathbf{2}$ & -17.31 & -17.25 & -17.37 \\
\hline $\mathbf{3}$ & -17.75 & -17.39 & -17.55 \\
\hline Delta & 1.01 & 0.23 & 0.67 \\
\hline Rank & $\mathbf{1}$ & $\mathbf{3}$ & $\mathbf{2}$ \\
\hline
\end{tabular}

The following Table 3 shows the current is the most significant factor and has major effect on surface roughness with $63.15 \%$ contribution. Voltage is the second most significant factor for surface roughness with a contribution of $29.63 \%$. Pulse on durationTime has least effect on surface roughness with $3.10 \%$ contribution.

Table 3 ANOVA for Surface Roughness

\begin{tabular}{|l|l|l|l|l|l|}
\hline $\begin{array}{l}\text { Sourc } \\
\text { e }\end{array}$ & $\begin{array}{l}\text { D } \\
\text { O } \\
\text { F }\end{array}$ & $\begin{array}{l}\text { Sum of } \\
\text { Square }\end{array}$ & $\begin{array}{l}\text { Adj } \\
\text { MS }\end{array}$ & $\begin{array}{l}\text { F } \\
\text { Valu } \\
\text { e }\end{array}$ & $\begin{array}{l}\text { Contribu } \\
\text { tion }\end{array}$ \\
\hline $\begin{array}{l}\text { Curr } \\
\text { ent }\end{array}$ & 2 & 1.09602 & $\begin{array}{l}0.5480 \\
1\end{array}$ & $\begin{array}{l}15.3 \\
3\end{array}$ & 63.15 \\
\hline Ton & 2 & 0.05369 & $\begin{array}{l}0.0268 \\
4\end{array}$ & 0.75 & 3.10 \\
\hline $\begin{array}{l}\text { Volta } \\
\text { ge }\end{array}$ & 2 & 0.51429 & $\begin{array}{l}0.2571 \\
4\end{array}$ & 7.19 & 29.63 \\
\hline Error & 2 & 0.07149 & $\begin{array}{l}0.0357 \\
4\end{array}$ & & 4.12 \\
\hline Total & 8 & 1.73549 & & & $100 \%$ \\
\hline
\end{tabular}

Figure 2 below illustrates the main effect plot for means for surface roughness. It is observed from the plots that the surface roughness increases with all the three WEDM parameters, but peak current and voltage are the major influencing parameters while pulse on time is the least affecting parameter. Larger crater are produced at higher current, pulse on duration and voltage, thus the surface obtained on machining is rough.

Better surface finish is obtained at lower values of WEDM parameters. 


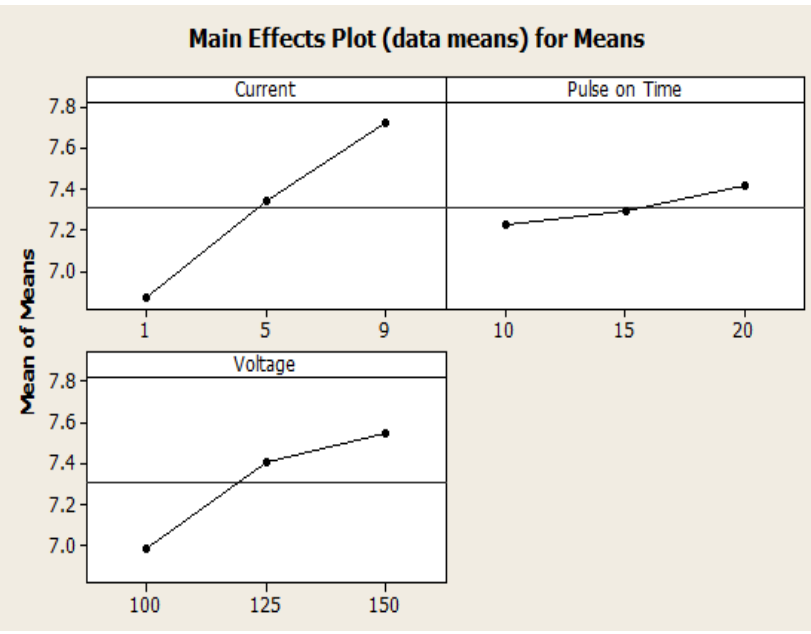

Fig 2: Main Effect Plot For Means For Surface Roughness

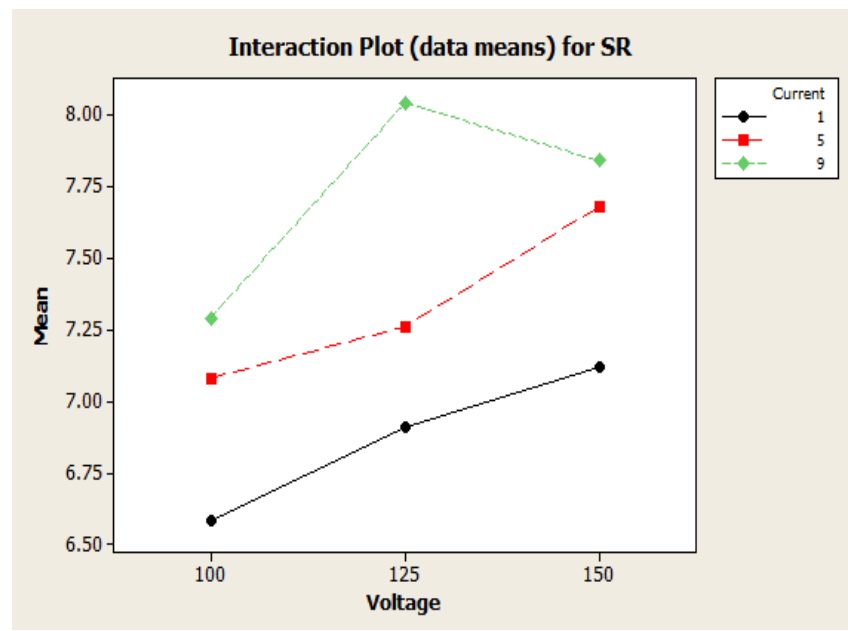

Fig 3: Relation between Surface Roughness and WEDM parameters

The above Figure 3 shows the interaction plot between surface roughness and WEDM parameters. It is observed that surface roughness increases with peak current at constant voltage. At higher value of current, the surface degradation initially increases with voltage. With further increase in voltage, the surface roughness reduces. This results because the debris of molten metal is not removed from the gap between tool and work, thus the intensity of sparks striking surface of the work piece are reduced and hence the surface roughness also get reduced.

\subsection{Surface Morphology}

Figure 4 (a) shows small crater. While with slight increase in current and pulse duration, crater size is observed to get increased as in Figure 4 (b) and 4 (c). With the highest level of current and pulse on duration, the crater size is largest of them as seen in Figure 4 (d) with parameters as $9 \mathrm{~A} / 20 \mu \mathrm{s} / 125 \mathrm{~V}$.
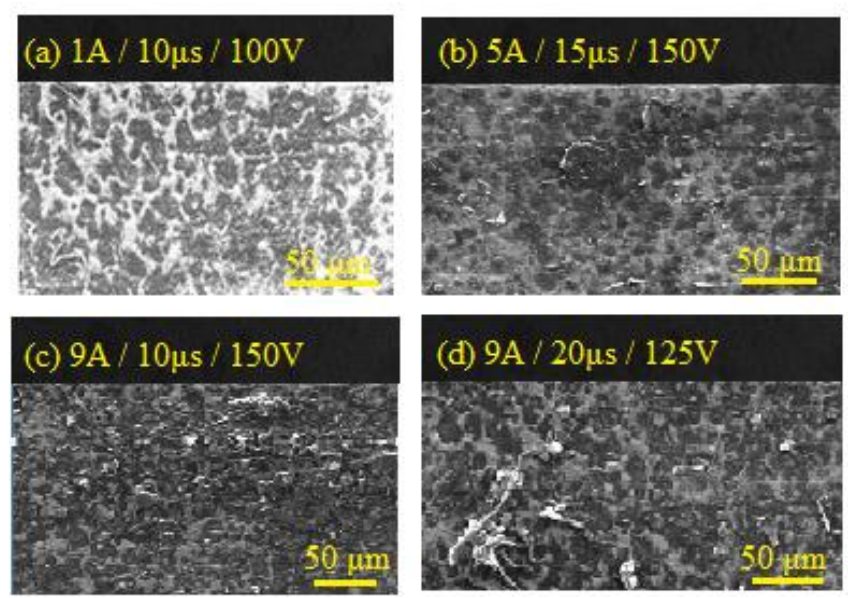

Fig 4: Morphology of WEDMed surface: (a) small crater $(1 \mathrm{~A} / 10 \mu \mathrm{s} / 100 \mathrm{~V})$, (b) slighty larger crater $(5 \mathrm{~A} / 15 \mu \mathrm{s} / 150 \mathrm{~V})$,

(c) $9 \mathrm{~A} / 10 \mu \mathrm{s} / 150 \mathrm{~V},(\mathrm{~d})$ larger crater $(9 \mathrm{~A} / 20 \mu \mathrm{s} / 125 \mathrm{~V})$

\section{CONCLUSION}

The experiments conducted on EN-40 using Brass wire have determined the relationship between WEDM parameters with surface roughness. The following conclusions are made:

1. Current is the major influencing factor for surface roughness while voltage is found to be the second most dominating factor for surface roughness.

2. Pulse on duration is the least dominating factor for the surface roughness of EN-40.

3. Smaller crater is obtained at low levels of WEDM parameters which results better surface finish.

\section{REFERENCES}

[1]. Manoj Malik, Rakesh Kumar Yadav, Nitesh Kumar, Deepak Sharma, Manoj; "Optimization of process parameters of Wire EDM using Zinc-Coated Brass wire", IJATER ISSN No: 2250-3536 Volume 2, Issue 4, July 2012.

[2]. K. Kumar, R. Ravikumar; "Modeling and Optimization of Wire EDM Process", IJMER, Vol. 3, 2013; ISSN: 2249-6645.

[3]. H. Singh, R. Garg "Effects of process parameters on material removal rate in WEDM", Journal of Achievements in Materials and Manufacturing Engineering VOLUME 32 ISSUE 1 January 2009.

[4]. Scott, D., Boyina, S., Rajurkar, K.P. (1991), "Analysis and optimization of Parameter Combination in Wire Electrical Discharge Machining", International Journal of Production Research, 29, 2189-2207.

[5]. Lin, H.C.,Lin, K.M., Chen, Y.S., Chu, C.L. (2005) "The wire electro-discharge machining characteristics of $\mathrm{Fe}-30 \mathrm{Mn}-6 \mathrm{Si}$ and $\mathrm{Fe}-30 \mathrm{Mn}-6 \mathrm{Si}-5 \mathrm{Cr}$ shape memory alloys", Journal of Materials Processing Technology, 161, 435-439.

[6]. Ramakrishnan, R. and Karunamoorthy, L. (2006), "Multi response optimization of wire EDM operations using robust design of experiments", International Journal of Advanced Manufacturing Technology, 29, 105-112.

[7]. Anoop Mathew Kurian, Dr. Binu C.Yeldose, Ernest Markose Mathew, "Effect of Wire EDM Parameters on 
Surface Roughness of Stainless Steel 15-5 PH”, IJEIT, Volume 4, Issue 2, August 2014.

[8]. Dhruv H. Gajjar, Jayesh V. Desai "Optimization of MRR, Surface Roughness and KERF Width in wire EDM Using Molybdenum Wire" IJRE, Vol. 4, Issue: 2, February : 2015.

[9]. R.Nagaraja, K.Chandrasekaran, S.Shenbhgaraj, "Optimization of parameters for metal matrix composite in Wire-EDM", IJESRT ISSN: 2277-9655 Nagarajal, 4(2): February, 2015

[10]. Parveen Kr. Saini, Mukesh Verma, "Experimental Investigation of Wire-EDM Process Parameters on MRR of Ti-6al-4v Alloy", IJITEE, ISSN: 2278-3075, Volume-4, Issue-5, October 2014.

[11]. Muhammad Qaiser Saleem, Muhammad Awais, "An Investigation for Better Machining Performance in Low

Range Tapering Mode", Technical Journal, University of Engineering and Technology, Vol. 20(SI) No.II(S)-2015.

[12]. Rajaneesh N. Marigoudara and Kanakuppi Sadashivappa, "Effect of Machining Parameters on MRR and Surface Roughness in Machining of ZA43/ SiCp Composite by WEDM", International Journal of Applied Science and Engineering 2013. 11, 3: 317-330. 